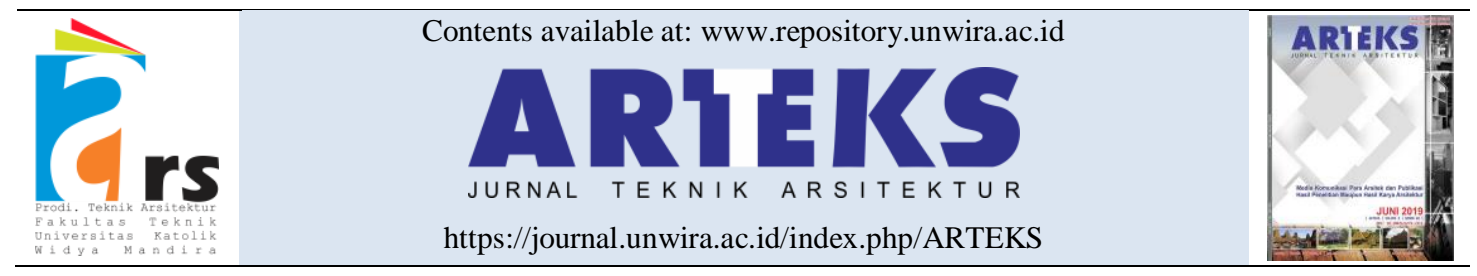

Research paper

doi: $10.30822 /$ arteks.v5i2.112

\title{
Akulturasi arsitektur lokal dan modern pada bangunan $P$-House, Salatiga
}

\section{Adityo Purnomo Aji, Bachtiar Fauzy*}

Program Studi Magister Arsitektur, Fakultas Teknik, Universitas Katolik Parahyangan

Jl. Ciumbuleuit no. 94, Bandung, Indonesia

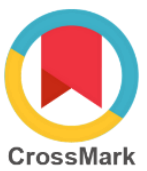

\begin{tabular}{l}
\hline ARTICLE INFO \\
\hline Article history: \\
Received August 21, 2019 \\
Received in revised form Sept. 10, 2019 \\
Accepted April 18, 2020 \\
Available online August 01, 2020
\end{tabular}

Keywords:
Acculturation of architecture
Archetypes
Architecture local
Architecture modern

*Corresponding author: Bachtiar Fauzy Program Studi Magister Arsitektur, Fakultas Teknik, Universitas Katolik Parahyangan, Indonesia

Email: bachtiarfauzy@yahoo.co.id

\author{
ABSTRACT \\ Local and modern acculturation architecture in P-House building, \\ Salatiga
}

Local and modern acculturated house concept is widely applied, one of which is the P-House P-House by Budi Pradono in Salatiga. Understanding about of the existence of local and modern elements in building design method is necessary to cultivate and strengthen the local value to be preserved in the modern era and to enrich the culture itself. In the case of this P-House study we can describe the existence of local and modern values in the building into the concept of tread, shape, space, structure, and material and then to find out the dominating aspect between local and modern values of the three building segments. The results of the process will demonstrate the dominance and placement of local and modern elements chosen by Budi Pradono in designing the P-House. The study used a descriptive method to describe the study object, analytic method to dissect the study object with theory, and interpretive method in drawing conclusions in an attempt to understand the dominance of local and modern values in the design method as well as to define the form of acculturation used or classified through the design of residential buildings.

\section{Pendahuluan}

Globalisasi menjadi fenomena open access yang saat memengaruhi segala bidang di dunia dan khususnya di Indonesia. Namun, dengan terbukanya masyarakat dalam menerima arus globalisasi muncul beberapa efek samping, atau dampak negatif akibat globalisasi. Selain memungkinkan masuknya teknologi yang berasal dari luar, globalisasi juga memengaruhi nilai dan kebudayaan yang dimiliki bangsa lain (Scholte 2005). Sehingga, masuknya arus globalisasi yang tidak terkontrol mampu mengakibatkan terkikisnya budaya lokal. Hal ini yang sudah seringkali terjadi pada masyarakat. Hilangnya nilai-nilai kelokalan pada kehidupan masyarakat mengakibatkan pergeseran budaya yang ada bahkan mengancam keberadaan budaya lokal itu sendiri (Djono, Utomo, and Subiyantoro 2012).

Melihat hal tersebut, maka dapat disimpulkan bahwa globalisasi tidak hanya memberikan dampak negatif, tapi juga dampak positif (Salura 2015). Dampak dari globalisasi tersebut, apabila mampu dimanfaatkan, berpotensi untuk mengembangkan teknologi, ide-ide, dan budaya termasuk dalam bidang arsitektur (Pawitro 2010). Namun tidak hanya semata-mata memanfaatkan globalisasi, tetapi juga harus mampu memadukannya dengan kearifan lokal yang ada agar, dampak negatif berupa hilangnya nilai kebudayaan yang dimiliki, mampu teratasi (Salura 2012). Maka peran atau usaha penggabungan kedua budaya tersebut penting sebagai sarana melindungi budaya, namun juga 
sebagai usaha untuk mengembangkan nilai kelokalan (Koentjaraningrat 2000; Salura, Clarissa, and Lake 2020).

Batasan dalam aspek fisik yang merupakan wujud arsitektur melalui aspek fungsi, bentuk, dan makna yang dapat dikenali melalui elemen pelingkup ruang bangunan, konsep ruang luar dan ruang dalam bangunan, struktur dan konstruksi, dan ragam hias. Sudut pandang nonfisik pada objek P-House, Salatiga karya Budi Pradono, dapat ditinjau dari fungsi bangunan serta aktivitas yang berlangsung dialamnya. Penerapan konsep arsitektur lokal dan modern dalam bangunan diharapkan mampu mengembangkan budaya lokal agar dapat tetap bertahan di era modern (Danes 2018; Salura and Clarissa 2018).

Keterkaitan antara kasus studi dengan teori dilakukan menggunakan metoda deskriptif dan analitik dimana, kasus studi akan dibahas dengan menjabarkan konsep-konsep yang berkaitan dengan desainnya, seperti konsep tapak, bentuk, ruang, struktur, material dan ornamen, sedangkan metoda analitik dilakukan dengan melakukan identifikasi archetypes yang ada pada objek studi terhadap arsitektur lokal dan modern yang diterapkan. Hasil dari analisa tersebut kemudian dapat dilakukan penarikan kesimpulan secara interpretative yang mampu menjelaskan pada $P$ House, Salatiga karya Budi Pradono (Tebbutt 2015), sehingga dapat ditarik benang merah yang mampu menjelaskan penerapan konsep arsitektur lokal dan modern sebagai cerminan semangat zaman.

Penelitian ini juga diharapkan mampu dijadikan rujukan bagi praktisi terutama untuk mengankat kelokalan dan nilai modern kedalam desain bangunan serta bagi akademisi untuk melakukan telaah yang lebih dalam terkait perpaduan kelokalan dan nilai modern sebagai bentuk usaha dalam mengebangkan arsitektur lokal di era modern.

\section{Budaya dan arsitektur lokal Jawa}

Dasar arsitektur lokal Jawa merupakan sebuah perjalanan dari berubahan pola pikir masyarakat Jawa pada penelitian ini, khususnya Yogyakarta, Jawa Tengah. Sebagai salah satu produk sebuah budaya, arsitektur lokal Jawa mampu mencerminkan nilai-nilai yang dianut oleh masyarakat pada masanya, sehingga dapat dipahami seperti apa dinamika sosial yang terjadi (Arinto 2018). Arsitektur lokal Jawa pada dasarnya juga memiliki pengaruh Hindu-Buddha (Sumardiyanto 2019). Sehingga pembahasan mengenail arsitektur lokal Jawa dapat dibagi menjadi dua bagian yaitu, rumah tradisional jawa dan Hindu-Buddha (Pitana 2007).

Pendekatan mengenai aspek fungsi lokal dilakukan dengan membedah kegiatan atau aktivitas masyarakat tradisional di Jawa. Pada umumnya konsep kegiatan masyarakat dilandasi oleh empat nilai, yaitu Tuhan, alam, sosial, dan diri sendiri. Keempat nilai dasar tersebut kemudian dapat dilihat melalui aktivitas yang dilakukan oleh masyarakat dalam kehidupannya sehari-hari (Refranisa 2019). Implementasi keempat nilai kedalam aktivitas sehari-hari menunjukkan adanya usaha menciptakan hubungan atau relasi antara manusia dengan keempat nilai tersebut yaitu, relasi antara manusia dengan Tuhan, relasi manusia dengan alam, relasi manusia dengan manusia lain, dan relasi manusia dengan dirinya sendiri (Kartono 2005).

Setiap kegiatan yang mencerminkan nilainilai relasi mampu tercermin ke dalam aktivitas sehari-hari. Kegiatan tersebut juga memberikan makna sendiri terhadap aktivitas yang berlangsung (Soehardi 2012). Keberadaan nilai dan norma mengenai relasi manusia dengan keempat elemen tersebut menjadi kunci dalam membaca budaya dan pedoman hidup masyarakat tradisional Jawa, sehingga munculnya makna yang menggambarkan tipe kegiatan atau aktivitas yang ada menjadi hal utama yang mampu mencerminkan keberadaan nilai relasi yang ingin dicapai masyarakat tradisional. Keempat bentuk relasi tersebut merupakan dasar dari pedoman hidup dan aktivitas masyarakat tradisional Jawa.

Bentuk-bentuk akulturasi

Akulturasi terbagi menjadi empat macam yaitu sinergi, adaptasi, adopsi, dan marginalisasi (Salura and Fauzy 2012). Sinergi adalah perpaduan nilai lokal dan nonlokal secara harmonis karena memiliki kekuatan yang sama (Brata 2016). Adaptasi adalah perpaduan kebudayaan lokal dan nonlokal dengan perbedaan dominasi dikarenakan unsur lokal yang lemah (Yusuf 2016). Adopsi adalah nilai lokal yang lemah berpadu dengan budaya nonlokal yang kuat, menghasilkan adaanya banyak unsur nonlokal yang diterapkan pada budaya lokal (Lalu and Fauzy 2020). Pemahaman tentang keempat bentuk akulturasi ini menjadi sangat penting karena diharapkan mampu memberikan pertimbagangan lebih dalam meciptakan sebuah rancangan objek arsitektur, juga diharapkan seorang perancang mampu memberikan serta 
menuangkan kreativitasnya kedalam desain bangunan (Salura 2010; Lalu and Fauzy 2020).

Archetypes dalam arsitektur

Archetype merupakan sebuah istilah yang datang dari Carl Jung seorang pakar psikologi yang berarti imaji atau citra tipe yang paling mendasar yang diperoleh dari kesadaran kolektif manusia (Arinto 2018). Evensen seorang pakar arsitektur yang mencoba menerapkannya dalam arsitektur dan menelusuri bentuk arsitektur secara mendetail (Arinto 2018). Secara garis besar membagi bangunan menjadi tiga elemen utama yaitu bawah, tengah dan atas. Kemudian mencoba menganalisis setiap elemen bangunan itu dengan pokok-pokok: "motion, weight, substance" yang disebut sebagai existencial expression (ThissEvensen 1987). Berdasar uraian tujuan penelitian ini, maka penelusuran aspek bentuk akan dilandaskan pada pendekatan architectural archetypes karena penelitian ini berusaha untuk mengungkap makna yang berada di belakang setiap bentuk.

\section{Metode penelitian}

Penelitian ini dapat dikategorikan kedalam penelitian kualitatif-deskriptif, dimana penelitian kualtatif cenderung pada subjektifitas dengan mendeskripsikan serta manganalisis bentuk akulturasi dengan cara mencari dominasi arsitektur lokal dan modern pada P-House, Salatiga karya Budi Pradono sebagai contoh hunian yang menerapkan konsep akulturasi arsitektur lokal dan modern.

Pemahaman mengenai metodologi yang akan digunakan ditujukan agar penelitian memiliki alur yang jelas dalam usaha mengumpulkan data. Penjabaran objek studi dilakukan dengan melakukan menjabaran elemen secara deskriptif yaitu konsep tapak, bentuk, ruang, struktur dan material. Desktripsi objek juga digunakan untuk menelaah ekspresi arsitektur lokal dan modern yang tercermin pada objek studi. Telaah analitis dilakukan dengan mengiris hasil deskripsi lokal dan modern yang ada pada objek kedalam tiga segmen utama bangunan kepala, badan, dan kaki.

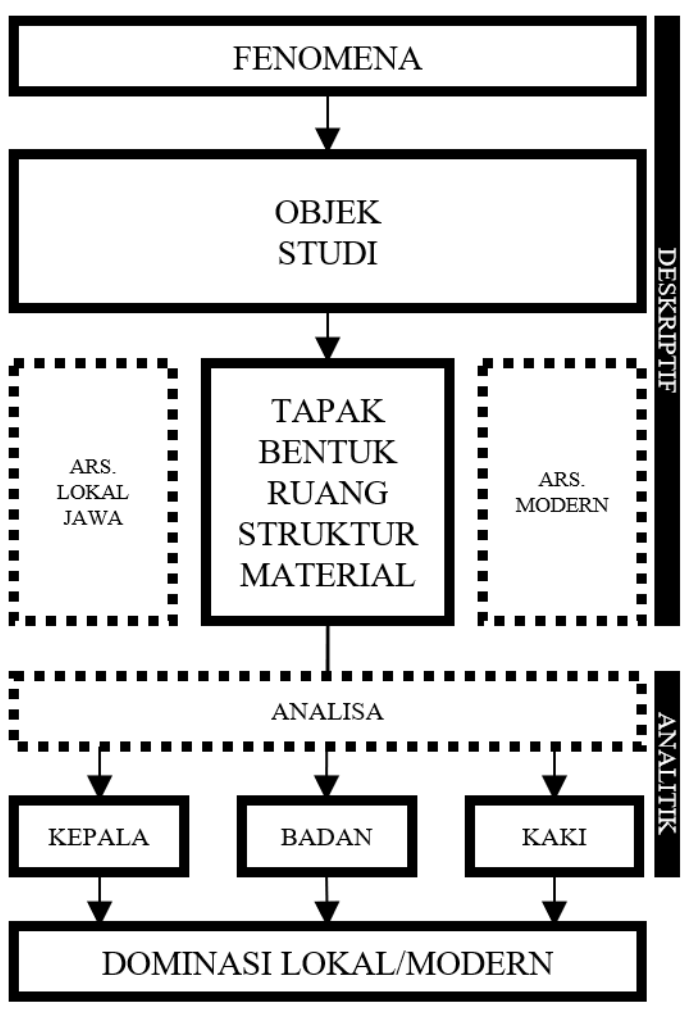

Gambar 1. Bagan alur penelitian

Hasil analisis yang didapat melalui pembedahan objek studi kedalam tiga bagian kepala, badan, dan kaki digunakan, untuk kemudian dilakukan penarikan kesimpulan secara interpretatif cerminan bentuk akulturasi pada ojek studi melalui dominasi arsitektur lokal dan modernnya.

\section{Temuan dan pembahasan}

Penerapan akulturasi arsitektur lokal dan modern menjadi konsep utama yang mencerminkan bangunan $P$-House, Salatiga karya Budi Pradono. Telaah lebih dalam tentang bangunan dapat dilakukan dengan memahami konsep yang mendasari bangunannya, dari segi tapak, bentuk, ruang, struktur dan konstruksi, material, serta ornamen dan pelingkup ruang. Objek studi merupakan sebuah hunian yang dibangun untuk seorang dosen dan keluarganya di Salatiga. Desain bangunan karya Budi Pradono ini menampilkan ekspresi arstiektur lokal dan modern secara bersamaan, sehingga membuat bangunan ini menjadi unik dan memiliki nilai lebih. 


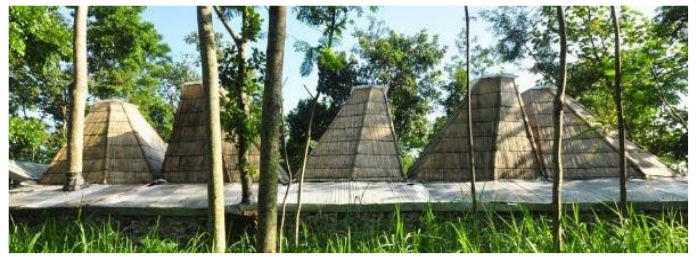

Gambar 2. $P$-House, Salatiga

Sumber: (Tebbutt 2015)

\section{Konsep tapak}

Konsep perancangan tapak pada bangunan $P$ House, Salatiga karya Budi Pradono secara garis besar menggunakan perpaduan arsitektur lokal dan modern. Elemen konsep arsitektur lokal pada bangunan ini menggunakan unsur yang setara dengan arsitektur pendopo atau joglo dalam rumah tradisional Jawa. Pemanfaatan dan interaksi ruang luar dan dalam bangunan merupakan cerminan dari rumah tradisional Jawa, namun diimplementasikan dengan ekspresi cerminan modern yang tidak kaku dan bentukbentuk asimetri.

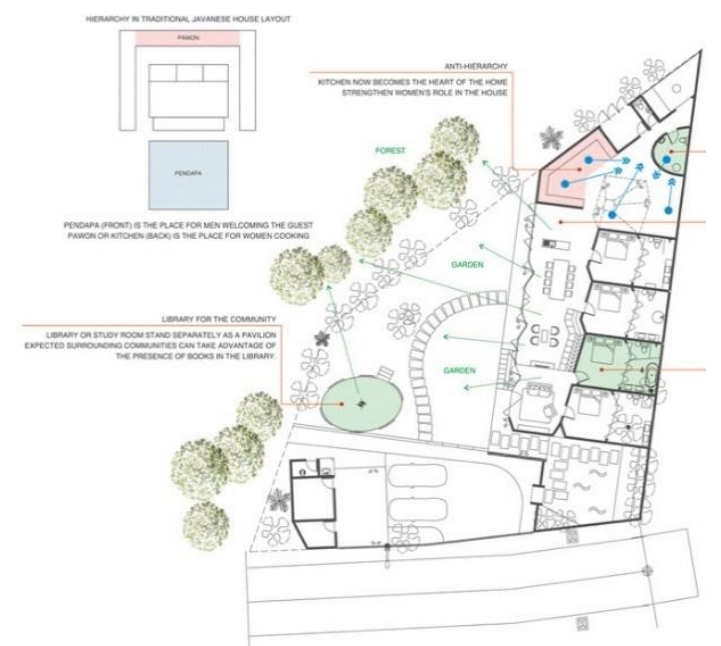

Gambar 3. Tapak P-House, Salatiga Sumber: (Tebbutt 2015)

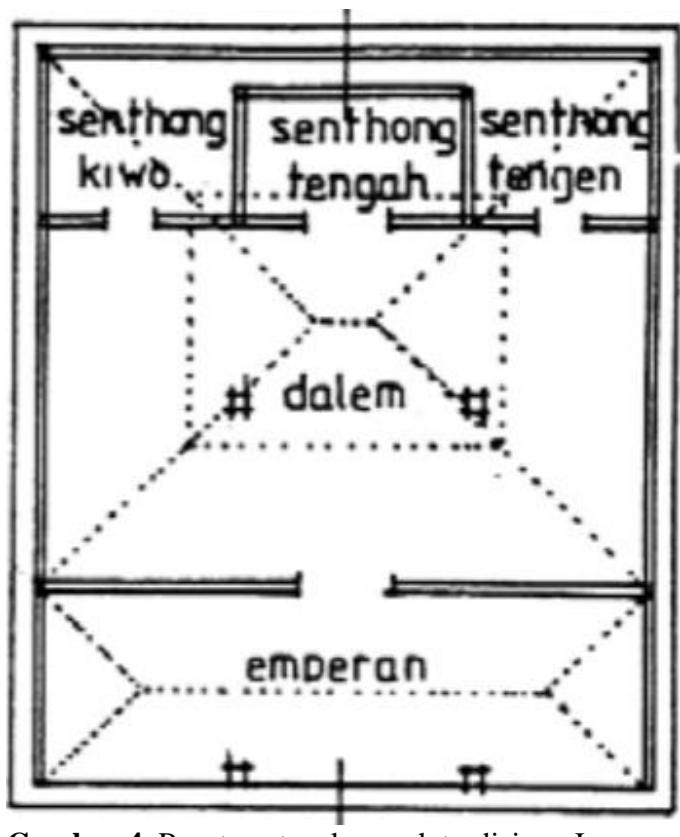

Gambar 4. Penataan tapak rumah tradisiona Jawa Sumber: (Kartono 2005)

Transformasi konsep tapak rumah tradisional joglo dalam bangunan P-House, Salatiga karya Budi Pradono terlihat dari penataan ruang luar dan dalam pada bangunan. Pada rumah tradisional ruang luar berada mengitari bangunan, sedangkan pada $P$-House, Salatiga karya Budi Pradono masa bangunan terpecah-pecah dan bersatu dalam lingkungan luar bangunan.

\section{Konsep bentuk}

Konsep bentuk bangunan pada P-House, Salatiga karya Budi Pradono banyak menerima inspirasi dari elemen lokal. Bentuk rumah merupakan ekspresi budaya lokal yang diwujudkan dalam bentuk baru yang lebih modern dan mencerminkan semangat zaman. Ekspresi lokal tercermin pada setiap elemen bangunan dari segi bentuk.

Bentuk bangunan tercermin pada ekspresi penutup atap bangunan. Dominasi bentuk atap merupakan salah satu ciri-ciri arsitektur lokal yang menyikapi iklim tropis sehingga berguna sebagai penyalur air hujan dan memberikan teritisan dari sinar matahari berlebih. 


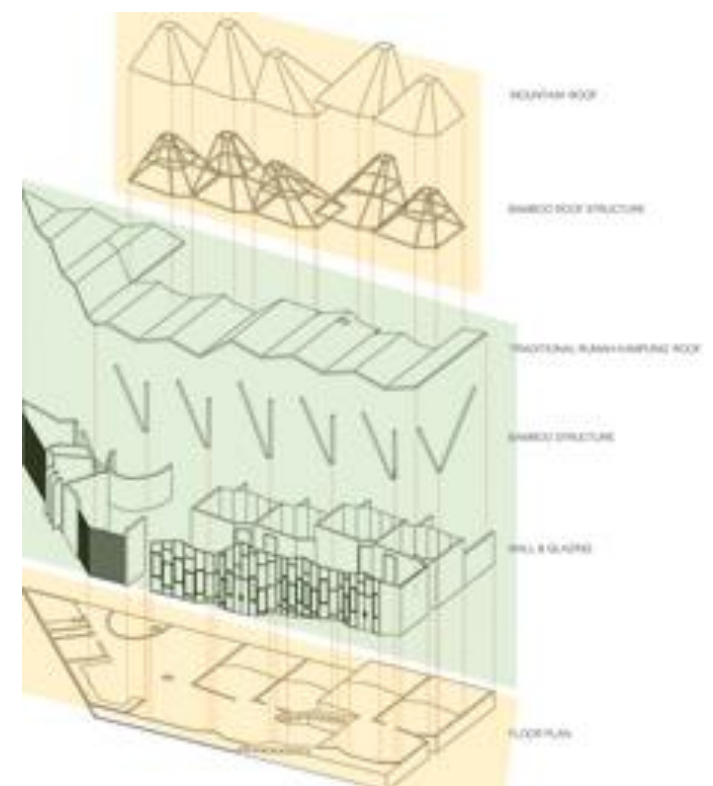

Gambar 5. Konsep bentuk P-House, Salatiga Sumber: (Tebbutt 2015)

Lapisan-lapisan yang membentuk bangunan mengekspresikan elemen arsitektur lokal dan budaya tradisional Jawa. Pada bagian atap bangunan unsur lokal terlihat dari analogi bentuk pegunungan yang didukung struktur bangunan dari bambu.

Kemiripan bentuk bangunan terlihat ketika membandingkan dengan bangunan tradisional Jawa. Atap berbentuk menyerupai gunungan. Ekspresi ini ditampilkan berulang pada $P$-House. Sedangkan penerapan fundamen bangunan menggunakan undakan juga serupa dengan rumah tradisional Jawa (Lihat gambar 6).

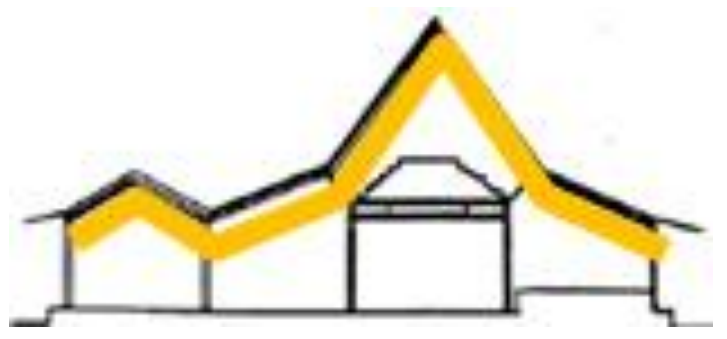

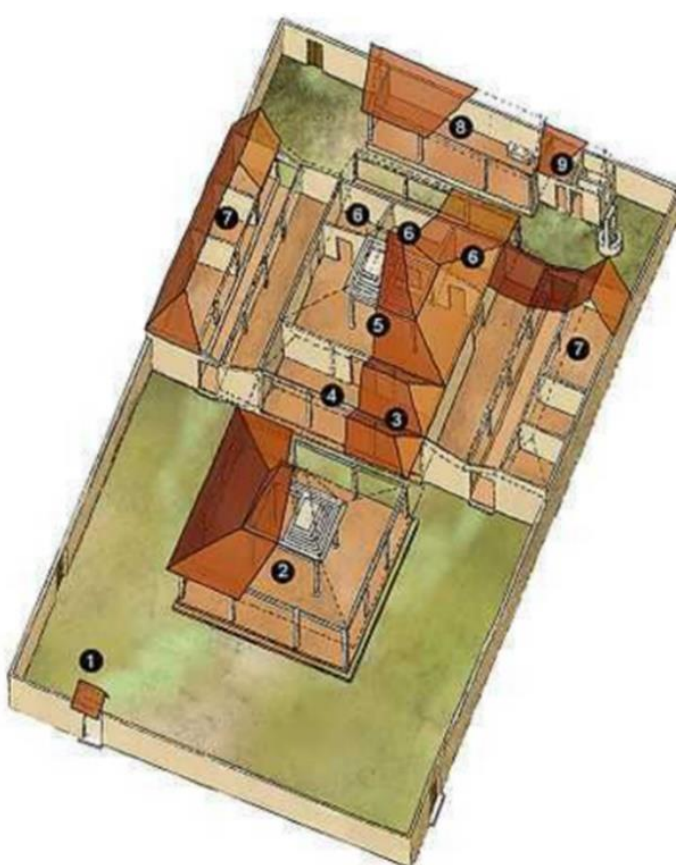

Gambar 6. Konsep bentuk rumah tradisional Jawa Sumber: (Kartono 2005)

\section{Konsep ruang}

Konsep ruang pada juga mengangkat nilai dan elemen lokal dengan perpaduan gaya modern. Penerapan unsur lokal pada P-House menggunakan gaya tradisional Jawa. Salah satunya pada penerapan hierarki dan zonasi bangunan. Pembagian hierarki ini dapat terlihat pada hierarki paling rendah yang terdapat pada area paling luar bangunan yaitu taman dan ruang luar lainnya. Hierarki kedua terletak pada area perantara antara ruang luar dan ruang dalam bangunan terletak pada garasi, ruang tamu, ruang makan, ruang keluarga dan lain-lain. Sedangkan hierarki paling tinggi terletak paling dalamn terdapat pada area kamar. Pembagian ruang menggunakan prinsip open plan pada ruang keluarga dan area makan serta dapur, sedangkan penggunaan sekat pada area kamar. Kedua konsep open plan dan umpak merupakan penerapan konsep lokal modern pada bangunan ini.

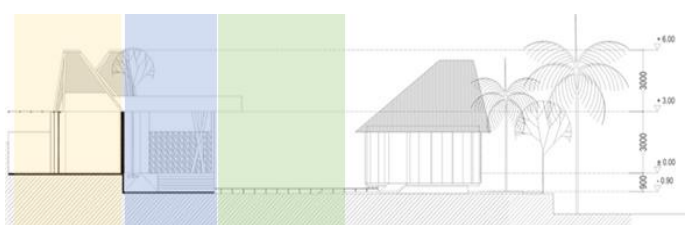

Gambar 7. Konsep ruang pada potongan $P$-House Sumber: (Tebbutt 2015) 


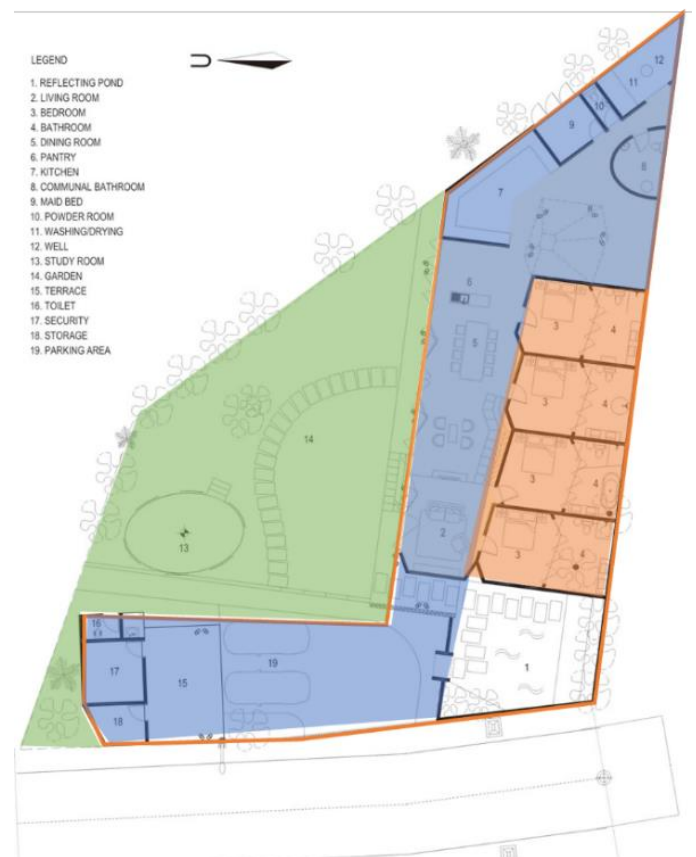

Gambar 8. Konsep ruang pada denah $P$-House Sumber: (Tebbutt 2015)

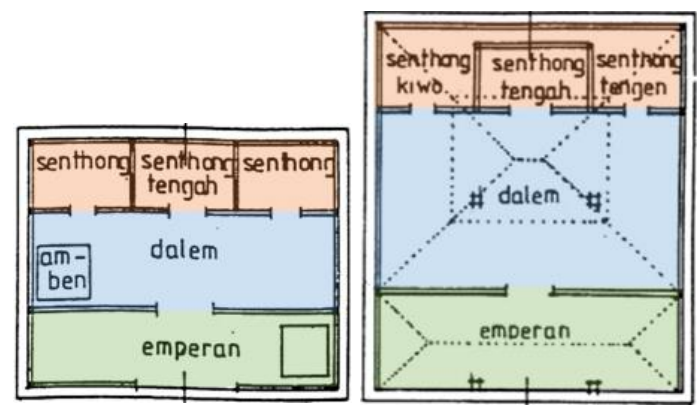

Gambar 9. Konsep ruang rumah tradisional Jawa Sumber: (Kartono 2005)

Selain itu konsep ruang pada P-House mengacu kepada prinsip pemnataan rumah tradsisional Jawa dan rumah modern. Penataan modern dapat dilihat melalui peletakkan ruang yang membagi area publik ke privat, dimana area privat diletakkan di area paling dalam, sedangkan area luar digunakan sebagai ruang publik dan servis. Pemanfaatan konsep ruang tradisional tampak dari hierarki ruang yang tercermin dari perbedaan ketinggian lantai, dimana area kamar memiliki hierarki paling tinggi yang kemudian didampingi oleh ruang keluarga dan semi-publik pada ketinggian yang lebih rendah, dan ruang luar berupa taman pada ketinggian paling rendah.

\section{Konsep struktur}

Struktur bangunan menggunakan material alam salah satunyaa dalah bambu. Struktur bambu digunakan sebagai struktur utama berupa kolom dan struktur atap. Ekspresi lokal juga semakin tercermin dengan pemanfaatan struktur yang menyerupai konstruksi tradisional. Penerapan yang cukup unik terlihat pada kolom bambu dimanapenerapannya seolah-olah langsung tertanam pada permukaan lantai beton. Penerapan kedua material ini mencerminkan dualitas antara lokal dan modern (nonlokal) yang berdampingan pada ruang keluarga dan ruang makan $P$-House, Salatiga.

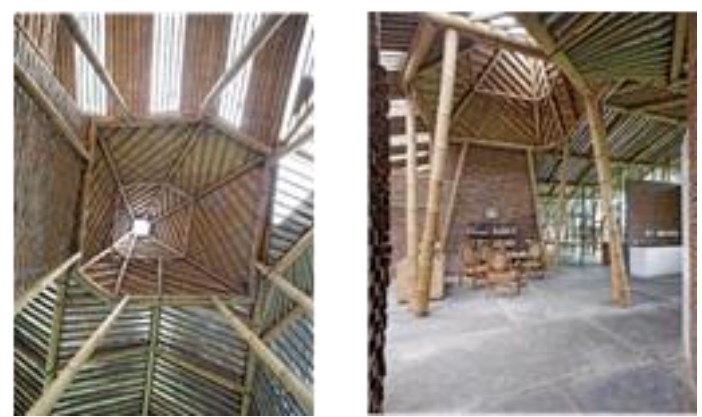

Gambar 10. Konsep struktur P-House, Salatiga

Sumber: (Tebbutt 2015)
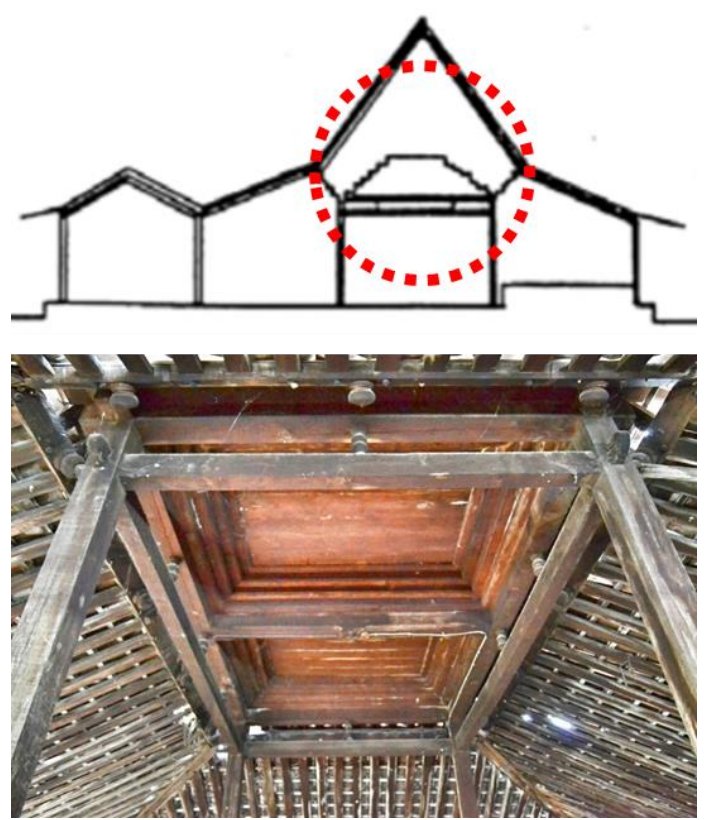

Gambar 11. Konsep struktur rumah tradisional Jawa Sumber: (Kartono 2005)

Penggunaan material alam untuk struktur bangunan menciptakan konstruksi khusus yang menghasilkan bentuk baru. Penggunaan material 
struktur pada $P$-House, juga menggunakan sistem alam.

\section{Konsep material}

Selain pada struktur bangunan, material lokal juga tercermin pada elemen lain. Pemanfaatan bata ekspose menjadi salah satu ekspresi lokal yang dimunculkan dalam bangunan. Pada bagian atap bangunan atap seolah-olah menggunakan ijuk sebagai penutup atap menyerupai rumah teradisional perkampungan Jawa.

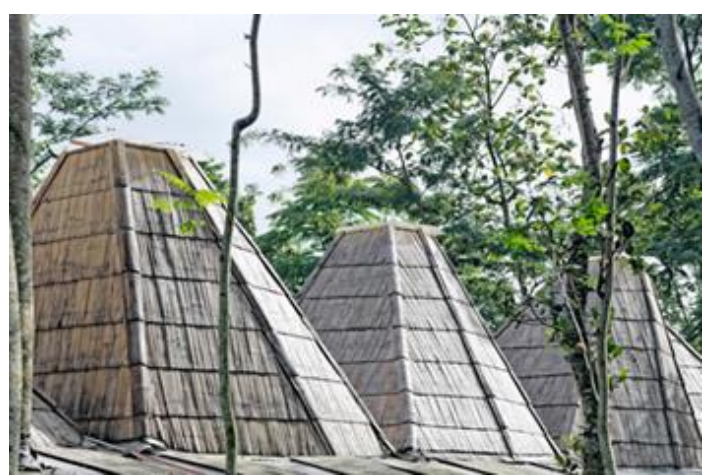

Gambar 12. Konsep material P-House, Salatiga Sumber: (Tebbutt 2015)

Penerapan unsur modern juga terlihat pada material kaca yang digunakan pada area publik bangunan. Elemen kaca menampilkan kesan industrial dengan frame besi. Sedangkan lantai bangunan juga menampilkan kesan industrial modern dengan penggunaan beton ekspose. Perpaduan kedua material utama ini mampu mencerminkan eskpresi kelokalan dan modernisme. Elemen bambu sebagai cerminan struktur lokal, sedangkan elemen besi, kaca, beton dan bata ekspose mencerminkan modernism.

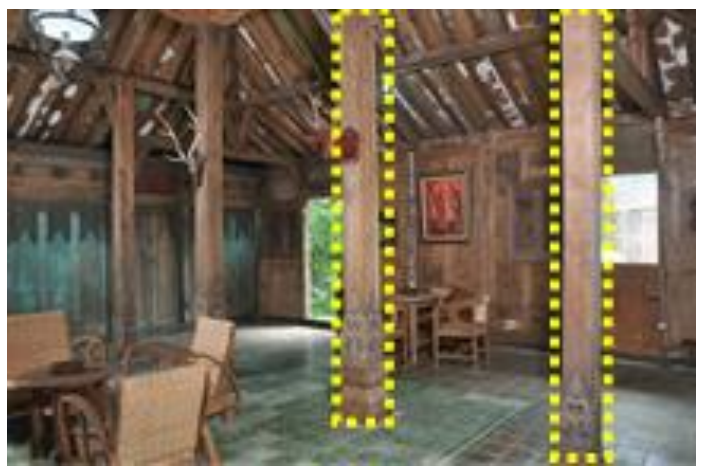

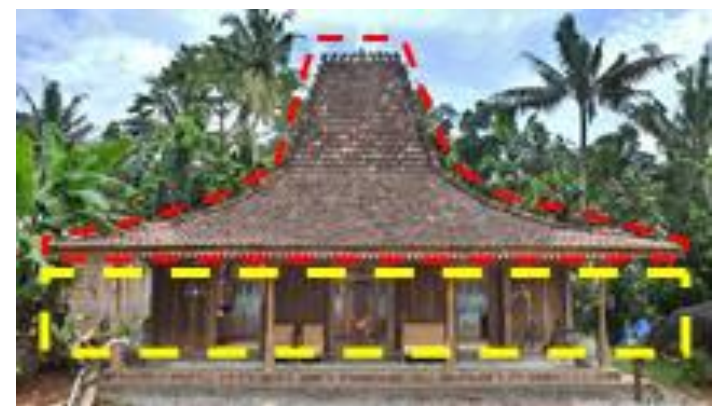

Gambar 13. Konsep material rumah tradisional Jawa Sumber: (Kartono 2005)

Penggunaan material tidak sepenuhnya menyerupai rumah tradisional Jawa yang didominasi kayu. Namun konsep utama penggunaan material yang ada disekitar tetap digunakan, pada kasus ini material yang digunakan ialah bambu dan pelepah daun. Material bambu digunakan untuk rangka atap utama dan kolom, sedangkan pelepah untuk penutup atap. Material modern juga digunakan dalam desain $P$-House, salah satunya adalah penggunaan kaca dan rangka besi. Kaca membawa kesan material industri yang kuat, hal ini didukung dengan keberadaan rangka besi yang modular. Material lantai bangunan menggunakan material yang berbeda dengan rumah tradisional jawa namun memiliki karakter yang serupa yaitu beton. Ekspresi yang diciptakan cukup serupa yaitu keras, massif dan dingin, namun pada rumah tradisional menggunakan batu alam. Pemanfaatan material alam menunjukkan apresiasi nilai lokal yang dipadukan dengan ekspresi modern.

\section{Dominansi arsitektur lokal dan modern}

Membaca dominasi budaya dalam sebuah objek arsitektur dapat dilakukan setelah menjabarkan konsep perancangan yang digunakan pada objek lalu dibandingkan dengan ekspresi lokal dan modern yang ada pada masingmasing segmen bangunan yaitu elemen kepala, elemen badan dan elemen kaki bangunan.

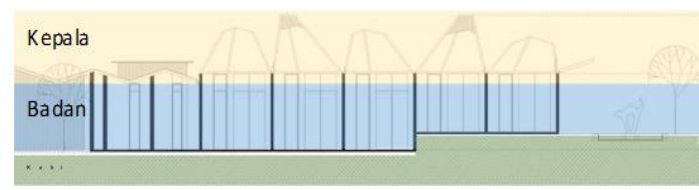

Gambar 14. Potongan $P$-House, Salatiga Sumber: (Tebbutt 2015)

Berdasarkan jabaran tersebut terapat uraian mengenai pembagian elemen bangunan menjadi elemen kepala, elemen badan, dan elemen kaki 
bangunan. Penerapan kelokalan dan nilai modern dapat ditelaah melalui penjabaran masing-masing elemen bangunan. Hasil analisis ini berfungsi untuk melakukan telaah lebih dalam dominasi akulturasi arsitektur lokal dan modern di dalam tiga elemen utama bangunan yaitu elemen kepala, elemen badan, dan elemen kaki.

\section{Elemen kepala}

Dominasi ekspresi bangunan P-House, Salatiga karya Budi Pradono mencerminkan bentuk akulturasi dengan penerapan bentuk arsitektur modern dengan tujuan mengangkat atau mencerminkan semangat zaman. Area elemen kepala bangunan dapat ditelaah melalui selubung atap dan bentuk atap bangunan. Bentuk atap bangunan terdiri dari dua bentuk, yaitu bentuk gunungan pada massa utama yang menaungi kamar utama, kamar tamu dan ruang makan, sedangkan atap berbentuk pelana berderet menaungi area ruang perantara seperti ruang keluarga, pintu masuk dan kamar mandi.

Bentuk atap menyerupai gunungan, merupakan penggambaran ulang alam sekitar Salatiga yang didominasi pegunungan. Ekspresi yang ditimbulkan juga didukung dengan material yang digunakan yakni menggunakan material lokal berupa bambu dan ijuk. Area atap yang menggunakan atap pelana berderet merupakan ekspresi arsitektur lokal yang menampilkan bentuk atap rumah di perkampungan sekitar.

Tabel 1. Dominasi arsitektur pada elemen kepala bangunan P-House, Salatiga
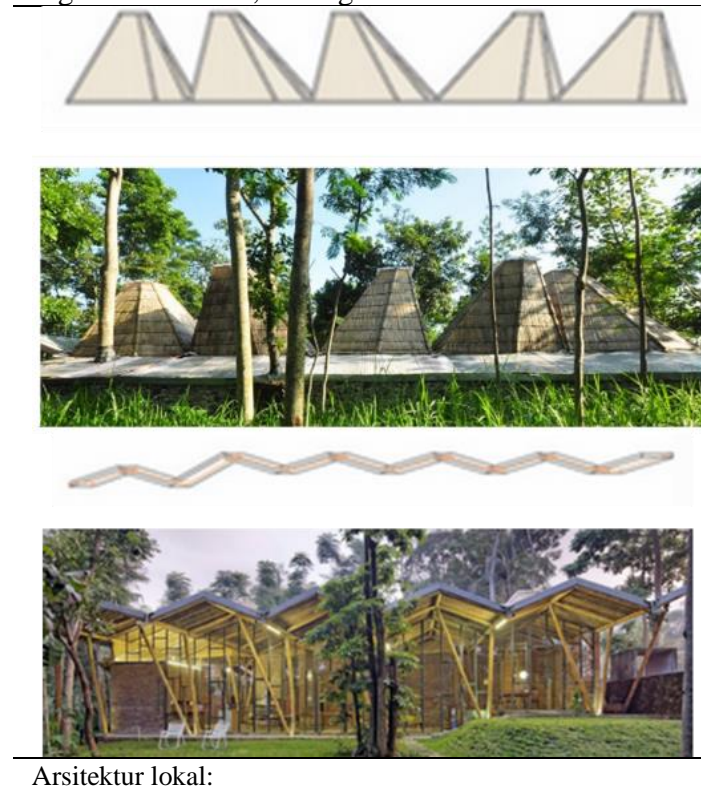

Arsitektur lokal:
1. Bentuk atap transformasi bentuk lokal gunungan dan atap rumah perkampungan;

2. Rangka atap struktur lokal;

3. Material penutup atap materal lokal;

4. Atap menunjukkan hierarki - rumah tradisional.

Arsitektur modern:

Pemanfaatan skylight pada atap menciptakan detail modern yang diselesaikan dengan konstruksi modern.

Elemen badan

Sosok badan bangunan menunjukkan bentuk modern melalui dominasi sosok geometris dan penggunaan material berupa beton ekspose, beton cetak, dan baja karat. Elemen arsitektur modern tersebut juga digunakan untuk menciptakan bentuk modern dengan karakter industrial yang kuat.

Area ruang luar, perantara dan ruang dalam mencerminkan kedua espresi lokal dan modern yang saling berdampingan. Ekspresi yang ditampilkan pada area badan bangunan didukung oleh dua ekspresi utama yaitu ekspresi lokal dan ekspresi modern. Elemen badan bangunan melingkupi area pelingkup dinding, ruang dalam dan luar, serta pemilihan funritur dan interior bangunan yang mencerminkan elemen lokal dan modern.

Elemen arsitektur modern tercermin pada area selubung badan bangunan dan ruang dalamn bangunan. Ruang dalam bangunan didominasi oleh penggunaan material industrial berupa panel kaca dengan frame besi yang memberikan kesan simple dan fungsional. Penggunaan matrial dinding menggunakan bata ekspose dan plester. Modernisme juga terlihat pada denah bangunan, dimana pembagian ruang menggunakan gaya open plan. Elemen arsitektur lokal tercermin melalui penggunaan material kolom dan plafond yang menggunakan bambu.

Pembagian hierarki ruang juga terlihat menggunakan nilai arsitektur lokal Jawa, dimana peletakkan ruang yang paling utama berada di area paling dalam atau privat.

Organisasi ruang pada P-House, Salatiga menggambarkan perpaduan hierarki organisasi ruang tradisional yang dipadukan dengan prinsip open plan modern. 
Tabel 2. Dominasi arsitektur pada elemen badan bangunan $P$-House, Salatiga
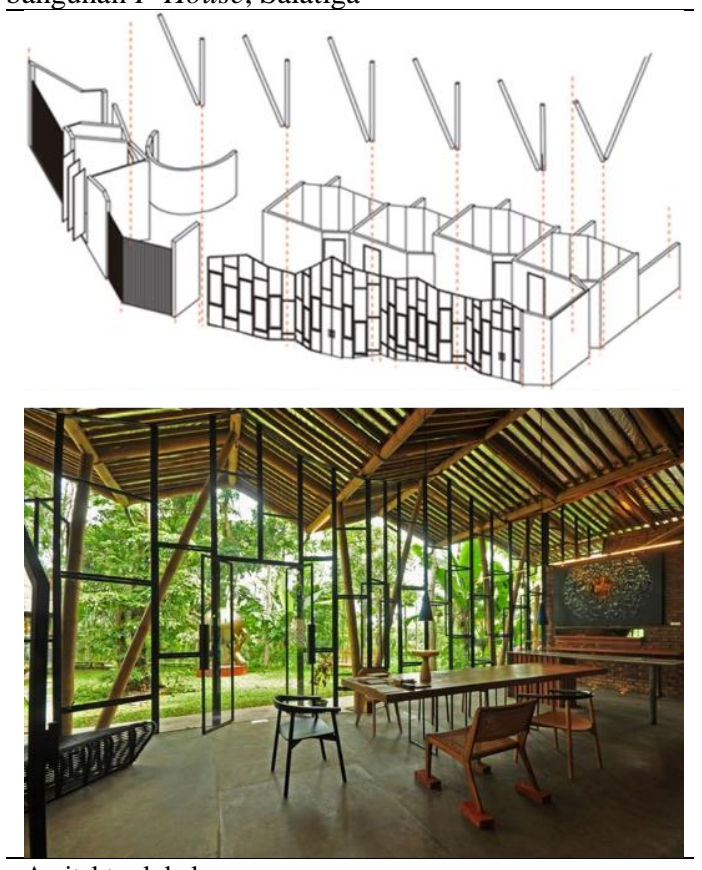

Arsitektur lokal:

1. Zonasi publik-privat menyerupai rumah tradisional dari luar ke dalam;

2. Material struktur utama (kolom) menggunakan material dan konstruksi alam, yaitu bambu (bangunan tradisional Jawa menggunakan kayu);

3. Material penutup atap materal lokal;

4. Penggunaan material bata ekspose.

Arsitektur modern:

1. Konsep ruang open plan pada area ruang keluarga, makan, dan dapur;

2. Hierarki tertinggi pada kamar utama;

3. Penggunaan material kaca dan rangka besi pada fasad.

\section{Elemen kaki}

Area elemen kaki bangunan melingkupi lantai dasar bangunan yang terdiri dari pelapis lantai dan permukaan tanah luar bangunan. Pada bangunan ini, elemen kaki bangunan merupakan bagian fundamen lantai. Bagian elemen kaki bangunan "Museum Monumen Yogya Kembali" dapat didefinisikan hanya berupa lantai dasar yang mewadahi bangunan tersebut. Namun konsep elemen kaki bangunan pada Museum Monumen Yogya Kembali dapat didefinisikan dengan cara yang berbeda. Karena, aktivitas yang terjadi pada Museum Monumen Yogya Kembali terdiri dari tiga layer.

Bila diartikan sebagai lantai dasar bangunan, maka bangunan $P$-House terdiri dari tiga level lantai bangunan yang didefinisikan sebagai elemen kaki. Elemen kaki adalah bagian yang menopang atau mewadahi aktivitas di dalamnya, sehingga, elemen kaki bangunan terpecah menjadi tiga layer tersebut.

Pada rumah tradisional Jawa segmen elemen kaki bangunan merupakan fundamen masif yang menjadi alas aktivitas di atasnya.

Elemen kaki bangunan $P$-House merupakan undakan-undakan yang memiliki ketinggian berbeda dan berurutan dari rendah ke tinggi, sehingga keberadaan segmen elemen kaki ini mampu menjadi penanda hierarki ruang yang ada di dalamnya. Hal tersebut juga ditemukan pada $P$ House, Salatiga karya Budi Pradono. Berdasarkan identifikasi pada rumah tradisional, maka elemen kaki bangunan pada $P$-House Salatiga karya Budi Pradono berada pada plat lantai masing-masing lantai. Undakan yang terjadi berubah menjadi perbedaan lantai yang tersusun secara horizontal, namun masih memiliki fungis yang sama yaitu menandakan hierarki ruang, dimana ruang tertinggi menjadi area yang dianggap paling sakral.

Elemen kaki pada Candi Borobudur sedikit berbeda dengan rumah tradisional Jawa. Pada Candi, elemen kaki bangunan merupakan undakan pertama yang menjadi podium Candi. Hal tersebut juga menjadi perbedaan apabila dibandingkan dengan $P$-House Salatiga karya Budi Pradono yang berupa undakan atau leveling lantai dari lantai dasar hingga lantai paling atas.

Tabel 3. Dominasi arsitektur pada elemen kaki bangunan $P$-House, Salatiga

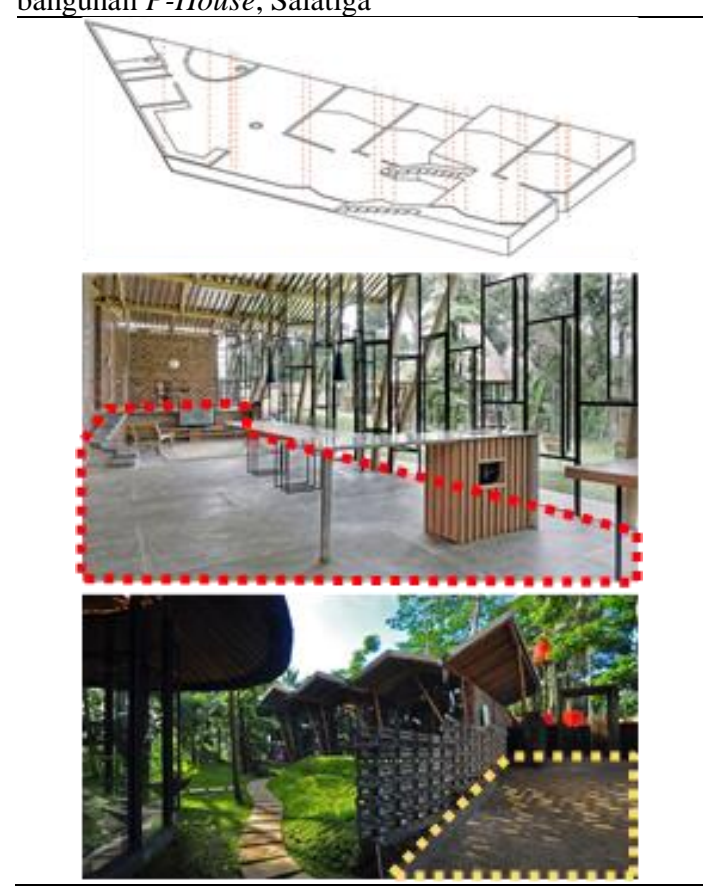


Arsitektur lokal:

1. Fundamen lantai menunjukkan hierarki melalui perbedaan ketinggian;

2. Penggunaan karakter fundamen lantai massif.

Arsitektur modern:

1. Material lantai menggunakan material beton ekspose cetak;

2. Definisi zona suatu ruang menggunakan perbedaan material.

Hasil analisis yang dilakukan, kemudian dapat digunakan untuk menentukan dominasi arsitektur lokal dan modern. Melalui analisis tersebut dapat diketahui konsep perancangan yang digunakan oleh Budi Pradono sebagai seorang arsitek dalam menentukan bentuk akulturasi yang tepat pada bangunannya seperti pada elemen kepala bangunan didominasi arsitektur lokal yang di transformasi, bagian elemen badan keberadaan lokal dan modern setara dan pada elemen kaki bangunan unsur lokal menjadi landasan perancangan.

\section{Kesimpulan}

Hasil analisa membaca konsep $P$-House, Salatiga karya Budi Pradono dengan menggunakan archetypes, teori arsitektur modern dan tradisional Jawa, maka dapat disimpulkan dominasi elemen arsitektur lokal dan modern sebagai berikut: (1) Elemen kepala. Keberadaan unsur lokal banyak ditemukan pada bagian elemen kepala bangunan. Bentuk atap bangunan merupakan transformasi dari bentuk atap gunugngan tradisional dan bentuk atap perkampungan Jawa. Rangka dan material atap juga menggunakan konsep yang serupa dengan rumah tradisional, yaitu menggunakan material dan konstruksi yang menyesuaikan dengan material alam, dalam ojek studi ini adalah bambu. Arsitektur modern juga muncul pada bagian atap bangunan berupa penggunaan skylight yang lazim digunakan pada bangunan dengan gaya modern untuk memasukkan cahaya kedalam bangunan; (2) Elemen badan. Unsur arsitektur lokal sangat kuat pada badan bangunan, terutama pada zonasi dan pembagian ruang serta aktivitas. Pengaturan alur publik ke privat disusun dari luar ke dalam, dimana area paling luar merupakan taman, area tengah area keluarga, makan dan dapur, sedangkan area paling dalam adalah kamar tidur. Prinsip kelokalan yang serupa dengan material dan konstruksi atap juga ditemukan pada kolom bangunan yang menggunakan bambu. Elemen arsitektur modern ditemukan pada bukaan yang menggunakan kaca dan rangka besi; (3) Elemen kaki. Fundamen lantai bangunan menggunakan material masif yang menyerupai karakter fundamen rumah tradisional Jawa. Penggunaan fundamen ini mendukung konsep tradisional yaitu penentuan hierarki menggunakan perbedaan ketinggian level lantai bangunan. Namun, yang membedakan dengan rumah tradisional Jawa adalah pada rumah tradisonal Jawa hierarki tertinggi pada ruang ibadah, sedangkan pada $P$ House terdapat pada kamar tidur. Material yang digunakan cukup berbeda karena menggunakan beton ekspose cetak sedangkan pada rumah tradisonal menggunakan batu alam. Fundamen lantai untuk mendefinisikan perbedaan ruang.

Kesimpulan penelitian ini kembali pada konsep akulturasi arsitektur lokal dan modern bangunan $P$-House, Salatiga karya Budi Pradono dengan membaca dominasi elemen arsitektur lokal dan modern yang terbagi pada tiga segemen bangunan yaitu elemen kepala, elemen badan, dan elemen kaki.

Melalui pemahaman tersebut bangunan $P$ House, Salatiga karya Budi Pradono didominasi oleh nuansa lokal, dimana masih banyak nilainilai lokal yang diangkat kembali pada bangunan ini sebagai konsep hunian modern, sedangkan elemen modern terfokus pada area badan bangunan dan material yang digunakan.

Bentuk akulturasi arsitektur lokal dan modern tercermin pada atap bangunan, khususnya pada atap gunungan. Konsep yang diangkat adalah konsep lokal yang diaplikasikan menggunakan gaya modern, sehingga menciptakan bentuk baru.

\section{Referensi}

Arinto, Fransiscus Xaverius Eddy. 2018. 'Pelestarian Arsitektur Berdasarkan Architectural Architypes Melalui Metode Grafis'. ARTEKS : Jurnal Teknik Arsitektur 3 (1): 29-36. https://doi.org/10.30822/arteks.v3i1.52.

Brata, I. 2016. 'Kearifan Budaya Lokal Perekat Identitas Bangsa'. Jurnal Bakti Saraswati 5 (1): 9-16. https://jurnal.unmas.ac.id/index.php/Bakti/art icle/view/226/201.

Danes, Ir Nyoman Popo Priyatna. 2018. 'Ancient Architectural Influence Between Bali and Majapahit: Drawing Upon the Affinities with 
Ancient Indian Architecture and the Way It Is Developed in Bali'. In Cultural and Civilisational Links between India and Southeast Asia, 275-89. Singapore: Springer Singapore. https://doi.org/10.1007/978-98110-7317-5_16.

Djono, Djono, Tri Prasetyo Utomo, and Slamet Subiyantoro. 2012. 'Nilai Kearifan Lokal Rumah Tradisional Jawa'. Humaniora 24 (3): 269-78. https://doi.org/10.22146/jh.1369.

Kartono, J. Lukito. 2005. 'Konsep Ruang Tradisional Jawa Dalam Konteks Budaya'. Dimensi Interior 3 (2): 124-36. https://media.neliti.com/media/publications/2 17877-konsep-ruang-tradisional-jawa-dalamkont.pdf.

Koentjaraningrat. 2000. Kebudayaan, Mentalitas Dan Pembangunan. Jakarta: Gramedia Pustaka Utama.

Lalu, Efraim, and Bachtiar Fauzy. 2020. 'Dominasi Ragam Akulturasi Lokal-Moderen Pada Bangunan Casablancka Residence, Bali'. ARTEKS: Jurnal Teknik Arsitektur 5 (1): 67-74. https://doi.org/10.30822/arteks.v5i1.187.

Pawitro, U. 2010. 'Fenomena Post-Modernisme Dalam Arsitektur Abad Ke-21'. Jurnal Itenas Rekayasa 14 (1): 40-48.

Pitana, Titis S. 2007. 'Reproduksi Simbolik Arsitektur Tradisional Jawa: Memahami Ruang Hidup Material Manusia Jawa'. GEMA TEKNIK Majalah Ilmiah Teknik 10 (2): 12633.

http://puslit2.petra.ac.id/ejournal/index.php/g em/article/view/17615/17530.

Refranisa. 2019. 'Pola Permukiman Di Dusun Mantran Weran Magelang Dalam Bingkai Kebudayaan Jawa'. ARTEKS : Jurnal Teknik $\begin{array}{llll}\text { Arsitektur } & 3 & \text { (2): } & 159-70 .\end{array}$ https://doi.org/10.30822/arteks.v3i2.67.

Salura, Purnama. 2010. Arsitektur Yang Membodohkan. 1st ed. Bandung: CSS Publishing.

_. 2012. 'Sintesis Elemen Arsitektur Lokal Dengan Non Lokal, Studi Kasus: Gedung Sate Di Bandung, Gedung UPS Di Tegal'. Bandung.

- 2015. 'Rethinking Architectural Design Studio Education in Global Era'. International Journal of Academic Research 7 (3): 218-21.

Salura, Purnama, and Stephanie Clarissa. 2018. 'Interpreting Architectural Expression of
House of Representative Building, Case Study: East Java Provincial House of Representative Building in Surabaya, East Java, Indonesia'. Journal of Advanced Research in Dynamical and Control Systems, no. 02-Special Issue: 1543-52. https://www.jardcs.org/backissues/abstract.ph $\mathrm{p}$ ?archiveid $=4664$.

Salura, Purnama, Stephanie Clarissa, and Reginaldo Christophori Lake. 2020. 'The Application of Sundanese Vernacular Concept to The Design of Modern Building-Case Study: Aula Barat (West Hall) of Bandung Institute of Technology, West Java, Indonesia'. Journal of Design and Built Environment. Vol. 20.

Salura, Purnama, and Bachtiar Fauzy. 2012. 'The Architectural Adaptation of Javanese Ethnic Houses to the Architectural Influence of Arab Ethnic Houses in Gresik'. Journal of Applied Environmental and Biological Sciences.

Scholte, Jan Aart. 2005. Globalization: A Critical Introduction. 2nd ed. United Kingdom: Red Globe Press.

Soehardi. 2012. 'Nilai-Nilai Tradisi Lisan Dalam Budaya Jawa'. Humaniora 14 (3): 1-13. https://doi.org/10.22146/jh.v14i3.763.

Sumardiyanto, Bonifasius. 2019. 'Pengaruh Renovasi Terhadap Makna Rumah Tradisional Masyarakat Jawa, Kasus Studi: Kotagede Yogyakarta'. ARTEKS: Jurnal Teknik Arsitektur 3 (2): 113-28. https://doi.org/10.30822/arteks.v3i2.62.

Tebbutt, Luke. 2015. 'Budi Pradono Architects' Bamboo House Mimics the Shapes of Nearby Buildings and Mountains'. Dezeen. 2015. https://www.dezeen.com/2015/08/03/budipradono-architects-bamboo-dancingmountain-house-multiple-roof-funnelssalatiga-indonesia/.

Thiss-Evensen, Thomas. 1987. Archetypes in Architecture. Oxford: Oxford University Press.

Yusuf, Stephanie Arvina. 2016. 'Wujud Akulturasi Arsitektur Pada Aspek Fungsi, Bentuk, Dan Makna Bangunan Gereja Kristen Pniel Blimbingsari Di Bali'. ARTEKS : Jurnal Teknik ArsitekturJurnal Teknik Arsitektur 1 (2): 15-30. https://doi.org/10.30822/arteks.v1i1.22. 
ARTEKS : Jurnal Teknik Arsitektur, Volume 5 Issue 2 August 2020

pISSN 2541-0598; eISSN 2541-1217 